\title{
The number of antihypertensive agents simply reflects the grade and the risk of atherosclerosis in patients with type 2 diabetes mellitus
}

\author{
Hiroyuki Ito ${ }^{1^{*}}$, Mariko Abe ${ }^{1}$, Masahiro Shinozaki ${ }^{1}$, Takashi Omoto ${ }^{1}$, Shinya Nishio ${ }^{1}$, \\ Masahide Furusho $^{1}$, Shinichi Antoku ${ }^{1}$, Mizuo Mifune ${ }^{1}$, Michiko Togane ${ }^{1}$, Tsutomu Sanaka ${ }^{2}$ \\ ${ }^{1}$ Department of Diabetes, Metabolism and Kidney Disease, Edogawa Hospital, Tokyo, Japan; \\ *Corresponding Author: ito@edogawa.or.jp \\ ${ }^{2}$ Lifestyle-Related Disease and CKD Center, Edogawa Hospital, Tokyo, Japan
}

Received 7 August 2013; revised 2 September 2013; accepted 10 September 2013

Copyright (C) 2013 Hiroyuki Ito et al. This is an open access article distributed under the Creative Commons Attribution License, which permits unrestricted use, distribution, and reproduction in any medium, provided the original work is properly cited.

\begin{abstract}
Aims: The associations between the number of antihypertensive agents being taken by type 2 diabetic patients and 1) the grade of atherosclerosis according to non-invasive surrogate markers for atherosclerosis and 2) the other risk factor for atherosclerosis, were cross-sectionally investigated. Methods: The association between the blood pressure control and the clinical characteristics was evaluated in 1359 patients with type 2 diabetes mellitus. Results: The number of antihypertensive agents was $1.5 \pm 1.4$ (2.0 \pm 1.2 among the 990 patients with hypertension). The proportion of patients taking no antihypertensive agents was $29 \%, 22 \%$ were taking one, $29 \%$ were taking two and $21 \%$ of the patients were taking three or more antihypertensive agents. The value of the ankle-brachial pressure index significantly decreased with the increase in the number of antihypertensive agents even if the blood pressure was corrected to the target value. The values of brachial-ankle pulse wave velocity and carotid intima-media thickness were also increased. The prevalence of risk factors for atherosclerosis, such as obesity, hyperlipidemia, chronic kidney disease, hyperuricemia and anemia was significantly elevated with the number of agents. Conclusions: The number of antihypertensive agents simply reflects the grade and risk of atherosclerosis in patients with type 2 diabetes mellitus.
\end{abstract}

Keywords: Hypertension; Antihypertensive Agents; Intima-Media Thickness; Ankle-Brachial Pressure
Index; Pulse Wave Velocity

\section{INTRODUCTION}

It is well-recognized that atherosclerotic diseases are common in patients with type 2 diabetes mellitus. Hypertension is not only an independent risk factor for atherosclerosis, but is also common in the type 2 diabetic patients $[1,2]$. Furthermore, hypertension is a risk factor for the onset and progression of diabetic micro- and macrovascular complications, as well as hyperglycemia $[3,4]$. The risk for cardiovascular events synergistically increases in patients with both diabetes mellitus and hypertension [5]. Although the target blood pressure is recommended to be less than $130 / 80 \mathrm{mmHg}$ in order to prevent diabetic vascular events [6,7], hypertension is often resistant to treatment in patients with type 2 diabetes mellitus $[8,9]$. It is difficult to control blood pressure using single agents, and combination therapy is needed in many diabetic patients with hypertension $[9,10]$. When examining patients with hypertension resistant to antihypertensive agents, it is important to re-evaluate the various causes such as lifestyle, body weight, smoking habit and excessive alcohol consumption, in addition to re-considering the medication. These are also risk factors for cardiovascular diseases, as well as hypertension and diabetes [6,7], therefore, it is possible that subjects requiring the combination therapy with antihypertensive agents may also have advanced atherosclerosis. Although the associations of cardiovascular events with the level of blood pressure achieved by medication or with the type of antihypertensive agents used have been reported previously $[3,6,7,11-13]$, the relationship between atherosclerosis and the number of antihypertensive drugs required in the clinical setting has not yet been investigated. 
It is possible that hypertensive subjects requiring more antihypertensive agents show progressive vascular damage independent of the control of blood pressure.

In the present cross-sectional study, the associations between the number of antihypertensive agents being used by patients with type 2 diabetes mellitus and 1) the grade of atherosclerosis according to non-invasive surrogate markers for atherosclerosis and 2) the other risk factors for atherosclerosis were investigated. We consider that these results indicate the necessity of a more aggressive approach for the diabetic patients requiring intensive therapy for hypertension independently from the blood pressure control.

\section{METHODS}

A population of 2107 patients diagnosed with type 2 diabetes mellitus who underwent consecutive treatments in the Department of Diabetes, Metabolism and Kidney Disease of Edogawa Hospital, Tokyo, Japan between April 2008 and March 2011, were screened for this study. For diagnosis of chronic kidney disease (CKD), 89 patients without urinalysis findings were excluded from the study. Because it is considered that a certain amount of time is required to adjust the dosage of antihypertensive agents, 653 subjects who were treated for less than 12 months were excluded from the study. Also excluded were 6 subjects whose blood pressure data were absent from their medical records following 12 months of treatment in our department. Finally, the associations between the number of antihypertensive agents being used and the clinical characteristics of the patients were evaluated in 1359 subjects who were treated for more than 12 months in the present cross-sectional study.

The blood pressure was measured twice with the subjects in the sitting position after a 5 minute rest. The lower value of the two measurements was used for the study. Hypertension was defined as a SBP $\geq 140 \mathrm{mmHg}$ and/or a DBP $\geq 90 \mathrm{mmHg}$. The participants currently using antihypertensive medications were also classified as positive for hypertension. The diagnosis of hypertension for this cross-sectional study was performed according to the medical records at the final visit to our hospital. The target blood pressure was less than 130/80 $\mathrm{mmHg}$ according to the JNC7 [6] and the guidelines proposed by the European Society of Hypertension and of the European Society of Cardiology [7]. The selection of antihypertensive agents was determined by each patient's physician during the treatment period.

The patients were divided into two categories according to their blood pressure status. Categories 1 and 2 were defined to include the subjects showing 1) SBP $<130 \mathrm{mmHg}$ and DBP $<80 \mathrm{mmHg}$ and 2) $\mathrm{SBP} \geq 130$ $\mathrm{mmHg}$ or $\mathrm{DBP} \geq 80 \mathrm{mmHg}$, respectively.

The number of antihypertensive agents was expressed as the sum of the antihypertensive agents, such as thiazide diuretics, loop diuretics, aldosterone antagonists, alpha blockers, beta blockers, calcium channel blockers (CCBs), angiotensin-converting enzyme inhibitors (ACEIs), angiotensin II receptor blockers (ARBs), renin inhibitors, and centrally-acting adrenergic drugs that were being used.

The obese individuals were defined as those having a body mass index $\geq 25.0 \mathrm{~kg} / \mathrm{m}^{2}$.

The serum total cholesterol, LDL-cholesterol, HDLcholesterol and uric acid concentrations were measured with a TBA-200 FR NEO device using the Determiner L TC II, Determiner L LDL-C, Determiner L HDL-C and Determiner L UA instruments (Kyowa Medex Co., Ltd., Tokyo, Japan). Hyperlipidemia was defined by serum concentrations of total cholesterol $\geq 5.7 \mathrm{mmol} / \mathrm{L}$, a LDLcholesterol level $\geq 3.6 \mathrm{mmol} / \mathrm{L}$, or as patients who were already undergoing treatment with lipid-lowering agents. The triglyceride concentrations were not investigated in this study because fasting blood samples could not always be obtained for measurements. Hyperuricemia was defined by serum uric acid levels $>416 \mu \mathrm{mol} / \mathrm{L}$ or as patients using allopurinol according to the guidelines proposed by the Japanese Society of Gout and Nucleic Acid Metabolism [14].

Anemia was defined as a hemoglobin level $<135 \mathrm{~g} / \mathrm{L}$ in men and $120 \mathrm{~g} / \mathrm{L}$ in women according to the guidelines of the European Renal Association-European Dialysis and Transplantation Association [15] and the National Kidney Foundation [16].

The estimated glomerular filtration rate (eGFR) was calculated using the formula reported by Matsuo, et al. [17] This equation originated from the MDRD study group [18] arranged for Japanese individuals, and it is recommended by the Japanese Society of Nephrology: eGFR $\left(\mathrm{mL} / \mathrm{min} / 1.73 \mathrm{~m}^{2}\right)=194 \times \mathrm{Scr}^{-1.094} \times \mathrm{Age}^{-0.287} \times$ 0.739 (if female).

CKD was defined as a decreased eGFR $(<60 \mathrm{~mL} / \mathrm{min} /$ $1.73 \mathrm{~m}^{2}$ ) and/or a urinary albumin-to-creatinine ratio $(\mathrm{ACR})>30 \mathrm{mg} / \mathrm{g}$ creatinine $[18,19]$.

The HbAlc levels were determined by a high performance liquid chromatography method using an automated HLC-723G7 analyzer (Tosoh Corporation, Tokyo, Japan) and calibrated by the Japan Diabetes Society (JDS) standard calibrators.

The ankle-brachial pressure index (ABI) and brachialankle pulse wave velocity (baPWV), as indicators of atherosclerosis, were measured using a Form PWV/ABI, BP-203PRE II instrument (Omron Colin Co., Ltd, Bunkyo, Tokyo, Japan). The intima-media thickness (IMT) of the carotid artery was measured via ultrasonographic examinations by skilled laboratory technicians using an Aplio XV ultrasound machine (Toshiba Medical Systems Corp., Ohtawara, Tochigi, Japan) as described previously 
[20].

\subsection{Ethics Statement}

This study was conducted according to the principles expressed in the 2008 Declaration of Helsinki. The Ethics Committee of Edogawa Hospital approved the protocol of this study and waived the need for written informed consent because the data were analyzed anonymously for this cross-sectional study based on the data stored in the hospital database.

\subsection{Statistical Methods}

All data are shown as the means \pm SD. The KruskalWallis test and the $\chi^{2}$ test were used for among-group comparisons of the continuous and categorical variables, respectively. A stepwise multivariate analysis by the forward selection method was performed to determine the association of the value of surrogate markers with the risk factors for atherosclerosis. Differences of $P<0.05$ (two-tailed) were considered to be statistically significant. The statistical software package JMP, version 8.0 (SAS Institute, Cary, NC, USA), was used to perform all of the analyses.

\section{RESULTS}

Table 1 shows the clinical characteristics of the study patients. The mean observation period in the study subjects was $27 \pm 10$ months. Their mean blood pressure

Table 1. The clinical characteristics of the patients.

\begin{tabular}{|c|c|c|}
\hline & $\% /$ mean $\pm \mathrm{SD}($ median, range) & Number estimated (\%) \\
\hline Age (years) & $64 \pm 12(65,72)$ & $1359(100)$ \\
\hline Age $\geq 65$ years $(\%)$ & 51 & $1359(100)$ \\
\hline Men (\%) & 62 & $1359(100)$ \\
\hline Duration of diabetes mellitus (years) & $9.8 \pm 9.8(7,55)$ & $1095(81)$ \\
\hline Treatment for diabetes mellitus ( $\%)$ & & $1359(100)$ \\
\hline Diet only/OHA/insulin & $14 / 59 / 27$ & \\
\hline Body mass index $\left(\mathrm{kg} / \mathrm{m}^{2}\right)$ & $24.7 \pm 4.0(24.2,31.8)$ & $1344(99)$ \\
\hline Obesity (\%) & 42 & $1344(99)$ \\
\hline Systolic blood pressure (mmHg) & $131 \pm 16(130,155)$ & $1359(100)$ \\
\hline Diastolic blood pressure $(\mathrm{mmHg})$ & $74 \pm 12(74,83)$ & $1359(100)$ \\
\hline Hypertension (\%) & 73 & $1359(100)$ \\
\hline Serum total cholesterol $(\mathrm{mmol} / \mathrm{L})$ & $5.1 \pm 1.1(5.0,10.0)$ & $1202(88)$ \\
\hline Serum LDL-cholesterol (mmol/L) & $3.1 \pm 1.0(3.0,7.0)$ & $791(58)$ \\
\hline Serum HDL-cholesterol (mmol/L) & $1.5 \pm 0.4(1.4,3.3)$ & $952(70)$ \\
\hline Hyperlipidemia (\%) & 64 & $1358(100)$ \\
\hline Hemoglobin $(g / L)$ & $138 \pm 17(139,141)$ & $1342(99)$ \\
\hline Anemia (\%) & 24 & $1342(99)$ \\
\hline Serum uric acid $(\mu \mathrm{moL} / \mathrm{L})$ & $304 \pm 85(297,744)$ & $1343(99)$ \\
\hline Hyperuricemia (\%) & 18 & $1359(100)$ \\
\hline Serum creatinine $(\mu \mathrm{mol} / \mathrm{L})$ & $83.8 \pm 45.7(73.4,654.2)$ & $1359(100)$ \\
\hline $\mathrm{eGFR}\left(\mathrm{mL} / \mathrm{min} / 1.73 \mathrm{~m}^{2}\right)$ & $55 \pm 19(53.3,196.7)$ & $1359(100)$ \\
\hline Chronic kidney disease (\%) & 89 & $1162(86)$ \\
\hline $\mathrm{HbA} 1 \mathrm{c}(\%)$ & $7.3 \pm 1.1(7.0,8.7)$ & $1341(99)$ \\
\hline Ankle-brachial pressure index & $1.11 \pm 0.12(1.13,1.27)$ & $806(59)$ \\
\hline Brachial-ankle pulse wave velocity $(\mathrm{cm} / \mathrm{s})$ & $1780 \pm 405(1725,3075)$ & $800(59)$ \\
\hline Carotid intima-media thickness $(\mathrm{mm})$ & $1.03 \pm 0.26(1.00,1.65)$ & $485(36)$ \\
\hline
\end{tabular}

OHA: oral hypoglycemic agents, eGFR: estimated glomerular filtration rate. 
was $131 \pm 16 \mathrm{mmHg}$ in systole and $74 \pm 12 \mathrm{mmHg}$ in diastole. The mean blood pressure was $117 \pm 10 / 66 \pm 8$ $\mathrm{mmHg}$ and $141 \pm 13 / 80 \pm 11 \mathrm{mmHg}$ in the patients in Category 1 and 2, respectively. The proportion of the category 1 patients was $43 \%(n=587)$. The number of antihypertensive agents was $1.5 \pm 1.4$ among all subjects (2.0 \pm 1.2 among the 990 patients with hypertension). The number of antihypertensive agents used among hypertensive patients was not different between the subjects of Category $1(2.0 \pm 1.2, n=393)$ and Category $2(2.1 \pm$ $1.2, n=597)$.

The proportion of patients using no antihypertensive agents was $29 \%(n=390), 22 \%(n=298)$ were using one, $29 \%(n=391)$ were using two, and $21 \%(n=280)$ were using three or more antihypertensive agents. CCBs, ACEIs, ARBs and thiazide diuretics were used in $49 \%$, $18 \%, 50 \%$ and $7 \%$ of patients, respectively.

Figure 1 shows comparisons of surrogate markers for atherosclerosis among the groups according to the number of antihypertensive agents. The value of the ABI significantly decreased with the increase in the number of agents in both Category 1 and 2 patients $(P<0.01)$. The values of the baPWV and carotid IMT were also increased $(P<0.01$, respectively). The trends of these changes were similar even after dividing the patients by the categories of blood pressure status (Figure 2).

Figure 3 shows the prevalence of the risk factors for atherosclerosis among the groups according to the number of antihypertensive agents. The prevalence of patients aged $\geq 65$ years, obesity, hyperlipidemia CKD, hyperuricemia and anemia was elevated with the number of agents being used $\left(P<0.01\right.$, respectively, $\chi^{2}$ test). The number of antihypertensive agents was significantly associated with the values of the ABI $(P<0.01)$, baPWV $(P<0.01)$ and $\operatorname{IMT}(P=0.03)$ according to the stepwise regression analyses when the number of antihypertensive agents, age $\geq 65$, obesity, hyperlipidemia, CKD, hyperuricemia and anemia were included as the independent variables.

\section{DISCUSSION}

In the present study, the number of antihypertensive agents reflected the grade of atherosclerosis according to the values of the ABI, baPWV and carotid IMT, regardless of the control of blood pressure in the patients with type 2 diabetes mellitus. Therefore, it should be recognized that diabetic patients requiring combination therapy for hypertension are still exposed to the risk for vas cular events, even if their blood pressure is corrected to the target value. Furthermore, it might be necessary to consider the vascular protective effects, as well as the blood pressure lowering effect when selecting antihypertensive agents for these patients. Approximately half of the patients required two or more antihypertensive agents in the present study, as previously reported $[8,9]$. The
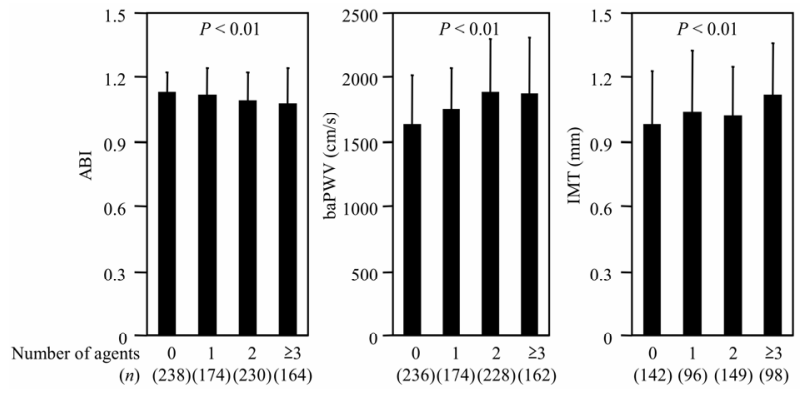

Figure 1. The comparisons of the surrogate markers for atherosclerosis in the groups according to the number of antihypertensive agents being used. ABI: ankle-brachial pressure index, baPWV: brachial-ankle pulse wave velocity, and IMT: carotid intima-media thickness.

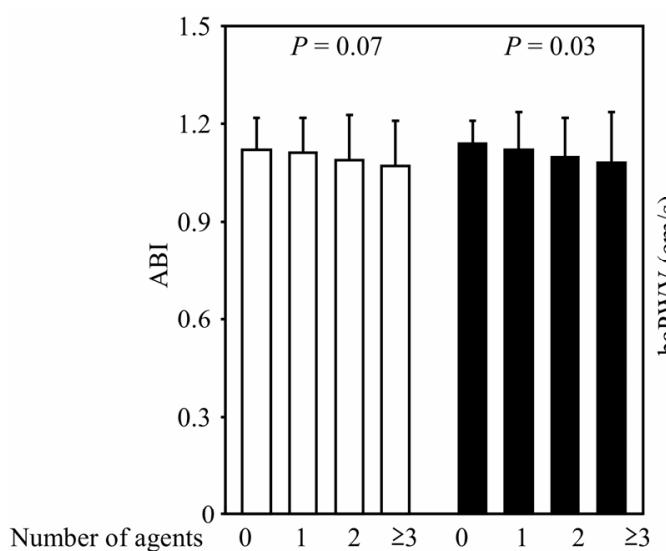

(n) $(129)(72)(87)(56)(109)(102)(143)(108)$

Category $1 \quad$ Category 2

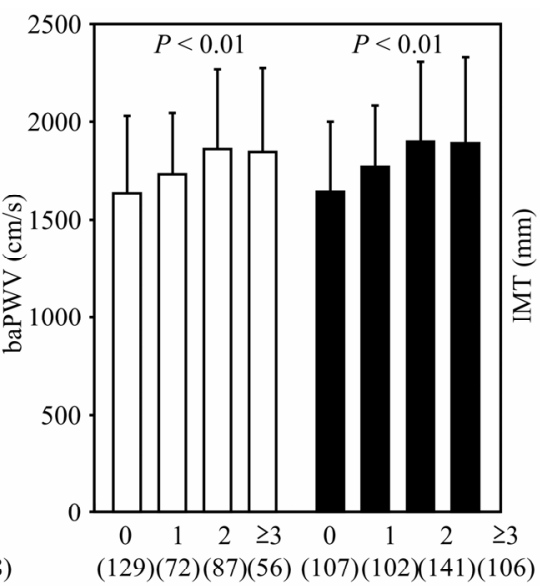

Category 1

Category 2

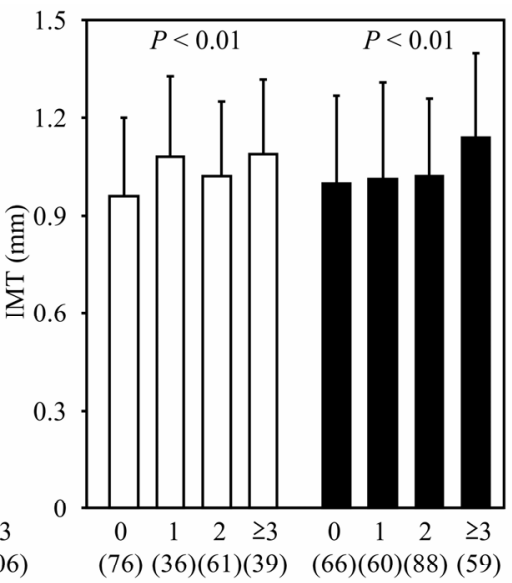

Category 1

Category 2

Figure 2. The comparisons of the surrogate markers for atherosclerosis in the groups according to the number of antihypertensive agents being used after subjects were divided into two categories based on their blood pressure status. ABI: ankle-brachial pressure index, baPWV: brachial-ankle pulse wave velocity, and IMT: carotid intima-media thickness. 


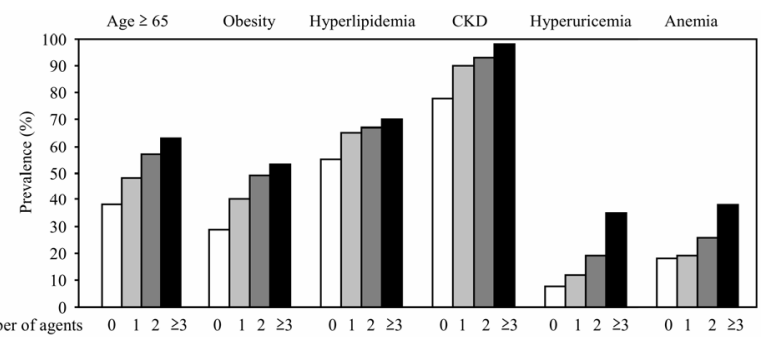

Figure 3. The prevalence of the risk factors for atherosclerosis in the groups according to the number of antihypertensive agents being used. CKD: chronic kidney disease.

number of antihypertensive agents being used in our study was similar to that in a report investigating the status of blood pressure in 466 diabetic and 2934 nondiabetic Japanese patients with hypertension [21].

Hyperglycemia, hypertension and obesity often coexist in an individual as an expression of insulin resistance [22-24]. Furthermore, elevated LDL-cholesterol [25], CKD [26,27], hyperuricemia [28] and anemia [29] have been described to be common and also be risk factors for vascular complications in patients with type 2 diabetes mellitus. The prevalence of these also increased with the increase in the number of antihypertensive agents used in the present study. The number of antihypertensive agents is considered to reflect the grade of atherosclerosis, because the vascular damage is often advanced or progressive in the patients with accumulation of these atherogenic conditions.

The ABI is the first choice non-invasive examination for assessing peripheral arterial disease. However, the application of this index should be carefully considered in patients with arterial calcification, such as those with the long-term morbidities of diabetes mellitus and with end-stage kidney disease on maintenance dialysis [30,31]. It is possible that the ABI might normalize from an originally low level, because calcification is more remarkable in the arteries close to the heart than in those in the ankles. Therefore, the statistical significances of the ABI among groups divided by the number of the antihypertensive agents might be clinically meaningful, even though the mean ABI remained within the normal range in the present study.

The present study has several important limitations. First, we did not determine the dose of antihypertensive agents required. The doses administered were dependent on the judgment of each patient's physician, as it was the decision to add another antihypertensive agent or increase the dose of a drug that was already being used. When the dose was increased, the enhanced antihypertensive therapy was not reflected in the number of antihypertensive agents. Second, the blood pressure measured at home was not evaluated in this study. Blood pressures measured in the hospital can demonstrate marked variability. If self-monitoring of blood pressure shows good control for hypertension, then physicians will generally not increase the therapy, even if the office blood pressure does not meet the target levels. This is considered to be one of the reasons why more than half of the patients remained within category 2 at the end of the observation in the present study. Third, the lower value of the two measurements was used for the evaluation of blood pressure in this study, although the JNC 7 recommends using the average of the values of at least two measurements [6]. Underestimation of the blood pressure might have led to the lower number of antihypertensive agents used in the present study subjects. Fourth, the lifestyle modifications, including diet therapy, were not determined in this study. The status of salt restriction might affect the number of antihypertensive agents being prescribed.

In conclusion, the number of antihypertensive agents simply reflects the grade and the risk of atherosclerosis in patients with type 2 diabetes mellitus. Even if the blood pressure is well controlled, treatments for the other metabolic factors, such as body weight, lipid profiles and serum uric acid, should be considered in the diabetic patients using multiple antihypertensive agents. Furthermore, intensive examinations for atherosclerosis are considered to be necessary. For example, it might be just an appropriate time to consider performing vascular examinations when the dose of antihypertensive agents is increased in diabetic patients with hypertension.

\section{ACKNOWLEDGEMENTS}

The authors thank Ms. Tomoko Koyanagi of the secretarial section of Edogawa Hospital for her valuable help in the data collection. The authors declare that they have no conflict of interest.

\section{REFERENCES}

[1] Kannel, W.B. (1989) Risk factors in hypertension. Journal of Cardiovascular Pharmacology, 13, S4-S10. http://dx.doi.org/10.1097/00005344-198900131-00003

[2] Iimura, O. (1996) Insulin resistance and hypertension in Japanese. Hypertension Research, 19, S1-S8. http://dx.doi.org/10.1291/hypres.19.SupplementI_S1

[3] UK Prospective Diabetes Study Group (1998) Tight blood pressure control and risk of macrovascular and microvascular complications in type 2 diabetes: UKPDS 38 . $B M J, 317,703-713$. http://dx.doi.org/10.1136/bmj.317.7160.703

[4] Holman, R.R., Paul, S.K., Bethel, M.A., Matthews, D.R. and Neil, H.A. (2008) 10-year follow-up of intensive glucose control in type 2 diabetes. New England Journal of Medicine, 359, 1577-1589. http://dx.doi.org/10.1056/NEJMoa0806470

[5] American Diabetes Association (1989) Role of cardiovascular risk factors in prevention and treatment of 
macrovascular disease in diabetes. Diabetes Care, 12, 573-579.

[6] Chobanian, A.V., Bakris, G.L., Black, H.R., Cushman, W.C., Green, L.A., Izzo Jr., J.L., Jones, D.W., Materson, B.J., Oparil, S., Wright Jr., J.T., Roccella, E.J., Joint National Committee on Prevention, Detection, Evaluation, and Treatment of High Blood Pressure. National Heart, Lung, and Blood Institute; National High Blood Pressure Education Program Coordinating Committee (2003) Seventh report of the Joint National Committee on Prevention, Detection, Evaluation, and Treatment of High Blood Pressure. Hypertension, 42, 1206-1252. http://dx.doi.org/10.1161/01.HYP.0000107251.49515.c2

[7] Mancia, G., De Backer, G., Dominiczak, A., Cifkova, R., Fagard, R., Germano, G., Grassi, G., Heagerty, A.M., Kjeldsen, S.E., Laurent, S., Narkiewicz, K., Ruilope, L., Rynkiewicz, A., Schmieder, R.E, Boudier, H.A. and Zanchetti, A., ESH-ESC Task Force on the Management of Arterial Hypertension (2007) 2007 Guidelines for the Management of Arterial Hypertension: The Task Force for the Management of Arterial Hypertension of the European Society of Hypertension (ESH) and of the European Society of Cardiology (ESC). Journal of Hypertension, 25, 1105-1187.

http://dx.doi.org/10.1097/HJH.0b013e3281fc975a

[8] Brown, M.J., Castaigne, A., de Leeuw, P.W., Mancia, G., Palmer, C.R., Rosenthal, T. and Ruilope, L.M. (2000) Influence of diabetes and type of hypertension on response to antihypertensive treatment. Hypertension, 35, 10381042. http://dx.doi.org/10.1161/01.HYP.35.5.1038

[9] Ito, H., Mifune, M., Abe, M., Oshikiri, K., Antoku, S., Takeuchi, Y., Togane, M., Ando, S. and Tsugami, E. (2012) Hypertension resistant to antihypertensive agents commonly occurs with the progression of diabetic nephropathy in Japanese patients with type 2 diabetes mellitus: A prospective observational study. BMC Nephrology, 13, 48. http://dx.doi.org/10.1186/1471-2369-13-48

[10] Bakris, G.L., Williams, M., Dworkin, L., Elliott, W.J., Epstein, M., Toto, R., Tuttle, K., Douglas, J., Hsueh, W. and Sowers, J. (2000) Preserving renal function in adults with hypertension and diabetes: A consensus approach. American Journal of Kidney Diseases, 36, 646-661. http://dx.doi.org/10.1053/ajkd.2000.16225

[11] Yusuf, S., Sleight, P., Pogue, J., Bosch, J., Davies, R. and Dagenais, G. (2000) Effects of an angiotensin-convertingenzyme inhibitor, ramipril, on cardiovascular events in high-risk patients. New England Journal of Medicine, 342, 145-153.

http://dx.doi.org/10.1056/NEJM200001203420301

[12] ALLHAT Officers and Coordinators for the ALLHAT Collaborative Research Group (2002) Major outcomes in high-risk hypertensive patients randomized to angiotensin-converting enzyme inhibitor or calcium channel blocker vs diuretic: The antihypertensive and lipid-lowering treatment to prevent heart attack trial (ALLHAT). JAMA, 288, 2981-2897. http://dx.doi.org/10.1001/jama.288.23.2981

[13] Wing, L.M., Reid, C.M., Ryan, P, Beilin, L.J., Brown, M.A., Jennings, G.L., Johnston, C.I., McNeil, J.J., Macdonald, G.J., Marley, J.E., Morgan, T.O., West, M.J.,
Second Australian National Blood Pressure Study Group (2003) A comparison of outcomes with angiotensin-converting-Enzyme inhibitors and diuretics for hypertension in the elderly. New England Journal of Medicine, 348, 583-592. http://dx.doi.org/10.1056/NEJMoa021716

[14] Japanese Society of Gout and Nucleic Acid Metabolism (2000) Guideline for the management of hyperuricemia and gout. 2nd Edition, Medical Review Co., Ltd, Tokyo.

[15] Locatelli, F., Covic, A., Eckardt, K.U., Wiecek, A., Vanholder, R., ERA-EDTA ERBP Advisory Board (2009) Anaemia management in patients with chronic kidney disease: A position statement by the Anaemia Working Group of European Renal Best Practice (ERBP). Nephrology Dialysis Transplantation, 24, 348-354. http://dx.doi.org/10.1093/ndt/gfn653

[16] National Kidney Foundation (2006) KDOQI clinical practice guidelines and clinical practice recommendations for anemia in chronic kidney disease. American Journal of Kidney Diseases, 47, S1-S146. http://dx.doi.org/10.1053/S0272-6386(05)01814-7

[17] Matsuo, S., Imai, E., Horio, M., Yasuda, Y., Tomita, K., Nitta, K., Yamagata, K., Tomino, Y., Yokoyama, H., Hishida, A., Collaborators developing the Japanese equation for estimated GFR (2009) Revised equations for estimated GFR from serum creatinine in Japan. American Journal of Kidney Diseases, 53, 982-992. http://dx.doi.org/10.1053/j.ajkd.2008.12.034

[18] Coresh, J., Astor, B.C., Greene, T., Eknoyan, G. and Levey, A.S. (2003) Prevalence of chronic kidney disease and decreased kidney function in the adult US population: Third National Health and Nutrition Examination Survey. American Journal of Kidney Diseases, 41, 1-12. http://dx.doi.org/10.1053/ajkd.2003.50007

[19] Levey, A.S., de Jong, P.E., Coresh, J., El Nahas, M., Astor, B.C., Matsushita, K., Gansevoort, R.T., Kasiske, B.L. and Eckardt, K.U. (2011) The definition, classification, and prognosis of chronic kidney disease: A KDIGO Controversies Conference report. Kidney International, 80, 1728. http://dx.doi.org/10.1038/ki.2010.483

[20] Ito, H., Komatsu, Y., Mifune, M., Antoku, S., Ishida, H., Takeuchi, Y. and Togane, M. (2010) The estimated GFR, but not the stage of diabetic nephropathy graded by the urinary albumin excretion, is associated with the carotid intima-media thickness in patients with type 2 diabetes mellitus: A cross-sectional study. Cardiovascular Diabetology, 9, 18. http://dx.doi.org/10.1186/1475-2840-9-18

[21] Obara, T., Ohkubo, T., Kikuya, M., Asayama, K., Metoki, H., Inoue, R., Oikawa, T., Murai, K., Komai, R., Horikawa, T., Hashimoto, J., Totsune, K., Imai, Y., J-HOME Study Group (2006) The current status of home and office blood pressure control among hypertensive patients with diabetes mellitus: The Japan Home Versus Office Blood Pressure Measurement Evaluation (J-HOME) study. Diabetes Research and Clinical Practice, 73, 276-283. http://dx.doi.org/10.1016/j.diabres.2006.01.015

[22] Reaven, G.M. (1988) Role of insulin resistance in human disease. Diabetes, 37, 1595-1607. http://dx.doi.org/10.2337/diabetes.37.12.1595

[23] DeFronzo, R.A. and Ferrannini, E. (1991) Insulin resis- 
tance. A multifaceted syndrome responsible for NIDDM, obesity, hypertension, dyslipidemia, and atherosclerotic cardiovascular disease. Diabetes Care, 14, 173-194. http://dx.doi.org/10.2337/diacare.14.3.173

[24] Kaplan, N.M. (1989) The deadly quartet: Upper body obesity, glucose intolerance, hypertriglyceridemia and hypertension. Archives of Internal Medicine, 149, 15141520. http://dx.doi.org/10.1001/archinte.1989.00390070054005

[25] Feingold, K.R., Grunfeld, C., Pang, M., Doerrler, W. and Krauss, R.M. (1992) LDL subclass phenotypes and triglyceride metabolism in non-insulin-dependent diabetes. Arteriosclerosis, Thrombosis, and Vascular Biology, 12, 1496-1502. http://dx.doi.org/10.1161/01.ATV.12.12.1496

[26] Ito, H., Takeuchi, Y., Ishida, H., Antoku, S., Abe, M., Mifune, M. and Togane, M. (2010) High frequencies of diabetic micro- and macroangiopathies in patients with type 2 diabetes mellitus with decreased estimated glomerular filtration rate and normoalbuminuria. Nephrology Dialysis Transplantation, 25, 1161-1167. http://dx.doi.org/10.1093/ndt/gfp579

[27] Ito, H., Oshikiri, K., Mifune, M., Abe, M., Antoku, S., Takeuchi, Y., Togane, M. and Yukawa, C. (2012) The usefulness of the revised classification for chronic kidney disease by the KDIGO for determining the frequency of diabetic micro- and macroangiopathies in Japanese pa- tients with type 2 diabetes mellitus. Journal of Diabetes and Its Complications, 26, 286-290.

http://dx.doi.org/10.1016/j.jdiacomp.2012.04.011

[28] Ito, H., Abe, M., Mifune, M, Oshikiri, K., Antoku, S., Takeuchi, Y. and Togane, M. (2011) Hyperuricemia is independently associated with coronary heart disease and renal dysfunction in patients with type 2 diabetes mellitus. PLoS One, 6, e2781. http://dx.doi.org/10.1371/journal.pone.0027817

[29] Ito, H., Takeuchi, Y., Ishida, H., Otawa, A., Shibayama, A. Antoku, S. Abe, M., Mifune, M. and Togane, M. (2010) Mild anemia is frequent and associated with micro- and macroangiopathies in patients with type 2 diabetes mellitus. Journal of Diabetes Investigation, 1, 273-278. http://dx.doi.org/10.1111/j.2040-1124.2010.00060.x

[30] Williams, D.T., Harding, K.G. and Price, P. (2005) An evaluation of the efficacy of methods used in screening for lower-limb arterial disease in diabetes. Diabetes Care, 28, 2206-2210. http://dx.doi.org/10.2337/diacare.28.9.2206

[31] Alnaeb, M.E., Crabtree, V.P., Boutin, A., Mikhailidis, D.P., Seifalian, A.M. and Hamilton, G. (2007) Prospective assessment of lower-extremity peripheral arterial disease in diabetic patients using a novel automated optical device. Angiology, 58, 579-585. http://dx.doi.org/10.1177/0003319707305685 